archiv euromedica |202I |vol. II |num.I |

http://dx.doi.org/10.35630/2199-885X/2021/11/1.34

\section{ORTHODONTIC TREATMENT FOR CONGENITAL CLEFT LIP AND PALATE IN CHILDREN}

\section{Mikhail Postnikov ${ }^{1 \otimes} \mathbb{D}$, Abdugafor Abdurakhmonov $^{2}$ (D), Natalia Pankratova ${ }^{1}$ (D), Svetlana Chigarina ${ }^{1}$ (D), Zulfiya Yakubova ${ }^{2}$ (D), Elizaveta Postnikova ${ }^{1}$ (D), Nadezhda Vorozheikina ${ }^{1}$ (D)}

\author{
${ }^{1}$ Samara State Medical University, Samara, Russia \\ ${ }^{2}$ Tajik State Medical University, Dushanbe, Tajikistan
}

$\triangle$ postnikovortho@yandex.ru

ABSTRACT - One in 1,000 newborns appears with a congenital maxillofacial anomaly, which accounts for about $0.04 \%$ of the world's entire population of the planet. Patients with cleft lip and palate have a significantly lower quality of life. Early orthodontic treatment (EOT) offered to children from the first days of life is a preparatory link in the preoperative period, laying favorable grounds for surgical intervention. EOT is a reasonable option to separate the oral cavity from the nasal cavity, to prevent consequent issues as well as to bring feeding back to the normal. This study involved clinical examinations and early orthodontic treatment of 84 children with congenital bilateral cleft upper lip and palate (CBCULP) from the first days of life and infants based on their referrals coming from all regions of the Republic of Tajikistan embracing the period of 2015 to 2019. Newborns with bilateral CULP within 5 days following birth, and infants who were referred for early orthodontic treatment, had their upper jaw cast model prepared using specially designed and modified spoons for taking impressions in case of cleft lip and palate. Within the study, unrelated marriages prevailed 3.4 times over related ones, which accounted for $22.6 \%$ of the cases examined. There were 1.58 times more boys than girls. Close relatives featured congenital maxillofacial abnormalities in $16.1 \%$ of the cases. The share of related marriages was $12.9 \%$. Follow-up period - 2016-2017; the patients' age — from the birth period to 1 year. The children were divided into two groups. In the main group, EOT was performed using a dental obturator for orthodontic treatment of children with CBCULP prior to the surgery $(n=43)$. In the comparison group, treatment was carried out in the conventional way $(n=41)$. Before the surgery, all the children were examined through clinical, anthropometric and photometric methods. The statistical processing of the obtained data revealed that before the no statistically significant differences identified. After the treatment, the age, the weight, as well as the height of the children expectably changed in both groups $(\mathrm{p}<0.001)$.

KEYW ORDS - congenital bilateral cleft upper lip and palate, orthodontic treatment, standardized spoon, dental obturator. start of treatment, the studied groups were comparable with
Received 02 February 2021;

Received in revised form 22 February 2021; Accepted 23 February 2021

\section{INTRODUCTION}

Dentofacial issues and deformities are ranked the third most popular among dental diseases giving way to dental caries and periodontal diseases [1-14]. Congenital bilateral cleft upper lip and palate (CBCULP) accounts for $12-25 \%$ of cases out of other types of cleft face and belongs to severe maxillofacial pathologies $[15,16]$. One in 1,000 children is born with the pathology in question, which is about $0.04 \%$ of the globe's population. Patients with cleft lip and palate suffer from significantly lower quality of life $[17,18]$. Early orthodontic treatment (EOT) for children from the first days of life is an element that serves a preparatory link within the preoperative period, which is a factor favorable for surgical intervention [19, 26-31]. EOT is a good option to treat cases implying separating the oral cavity and the nasal cavity, as well as to prevent secondary deformities and improve feeding [20-22].

\section{Aim of the study}

is to increase the effectiveness of orthodontic treatment offered to young children with CBCULP using specifically designed devices.

\section{MATERIALS AND METHODS}

A clinical examination and early orthodontic treatment were offered to 84 children with CBCULP, subject to their self-reports (age group - the birth time through infant age) embracing all regions of the Republic of Tajikistan within the period of 2015-2019. Newborns with CBCULP aged up to 5 days after birth and infants, who came seeking early orthodontic treatment, had their upper jaw models taken using alginate mass and spoons modified specifically to take impressions of cleft lips and palates (Certificate for innovation proposal \# 3297/R 512 of November 9, 2012) (Fig. 1) [23-25].

\section{RESULTS AND DISCUSSION}

Generalized archival data of 2,630 children with CBCULP who were brought to the clinic seeking respective help in the Republic of Tajikistan show that the total number of patients went up 1.79 times within in the period of 2009-2019. Boys accounted for $55.1 \%$ of the patients. The studied pathologies included: 


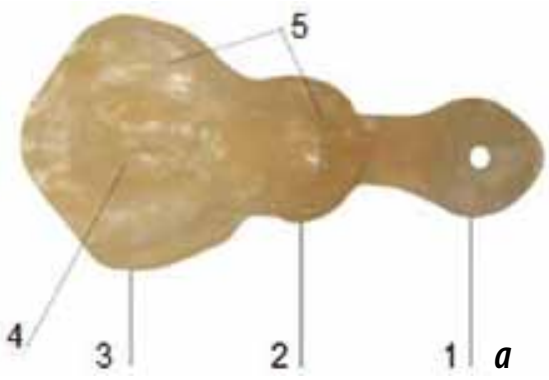

CUCULP (90.3\%) and CBCULP (9.7\%). The occurrence rate for the first pathology went up by 1.66 times, while for the other one the same increase index was 3.27 times (Fig. 2, 3).

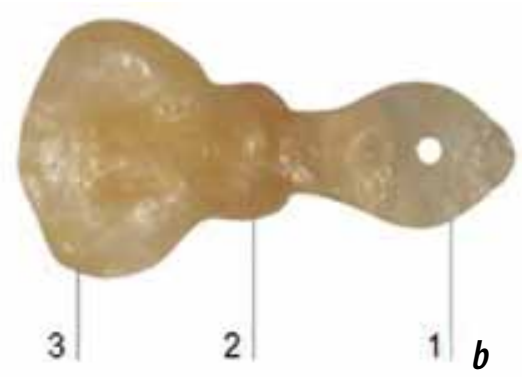

Fig. 1. Spoons modified to take impressions of cleft lips and palates (intermaxillary bone position in the middle of the upper jaw) ( $a$ view from inside, $b$ - view from outside): 1 - handle, 2 - intermaxillary plate, 3 - side board, 4 - middle protrusion, 5-alveolar and intermaxillary parts tray

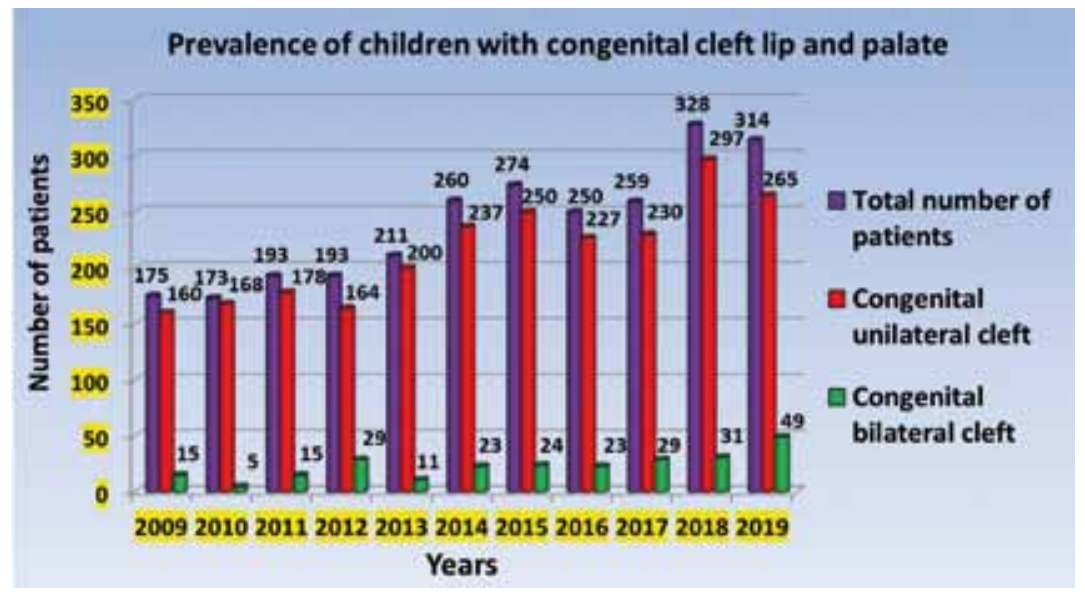

An analysis of the outcomes obtained through surveying mothers/parents of children with CBCULP revealed that $100 \%$ of the children were born in due time, while the social status of families and the de-
Fig. 2. Prevalence of children with congenital cleft of the upper lip and palate in the Republic of Tajikistan (City of Dushanbe) according to the data of appealability from 2009 to 2019

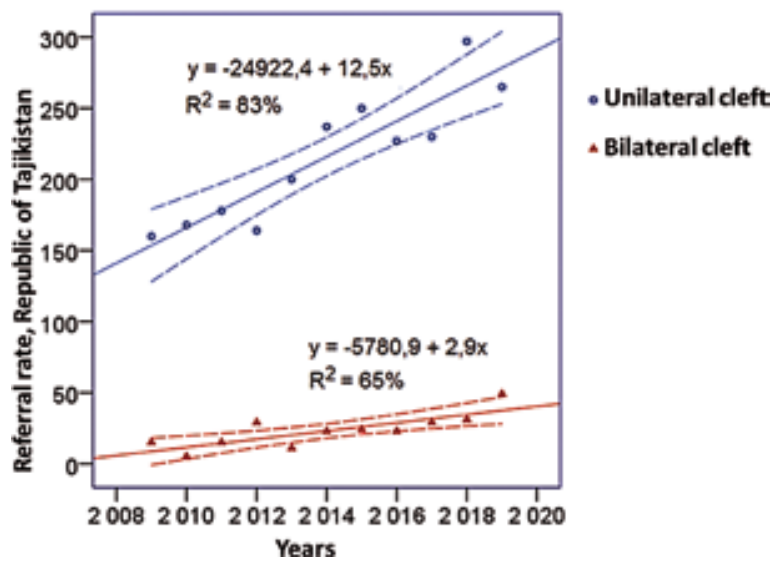

Fig. 3. Graphic representation of general data by the type of pathology in children with CULP based on referral in the Republic of Tajikistan (City of Dushanbe): $a$ - smoothing by a linear filter, $b$ - approximation by linear regression: regression lines and their $95 \% \mathrm{Cl}$, the resulting equations and their determination coefficients (R2) velopment forecast for the newborns were good. The parents' age at the time their respective child was born with CBCULP ranged from 20 to 43 , the average age of the mothers was 27.8 , the fathers' median age being 28.9. Unrelated marriages prevailed 3.4 times over related ones, which accounted for $22.6 \%$ of the case body. There were 1.58 times as many boys compared to girls. Closely related individuals were observed to have congenital maxillofacial issues in $16.1 \%$ of the cases. Related marriages accounted for $12.9 \%$.

Feeding of newborns was mostly artificial (93.5\%). Within their respective families, according to the order of birth, $32.3 \%$ of the newborns with CBCULP were first babies, of which $9.7 \%$ of the parents were related. The rates of the babies born second, third and fourth were $16.1 \%, 19.4 \%$, and $16.1 \%$, respectively. The seventh (3.2\%) and eighth (3.2\%) children in the family were born to parents aged 38 (mother) and 43 (father). The survey revealed that during pregnancy, 
expectant mothers were healthy in $51.6 \%$ of the cases; $25.8 \%$ were diagnosed with anemia; $19.4 \%$ of all the cases had acute respiratory viral infection (ARVI), another $3.2 \%$ of the cases suffering from herpes.

84 children with CBCULP underwent examination and treatment at the Shifobakhsh medical consulting office of the Department of Child and Adolescent Maxillofacial Surgery, Research Center, Republic of Tajikistan, with a follow-up period of 2016-2017. The patients' gender distribution was as follows: boys $-55 \%$, girls $-45 \%$. The patients' age ranged from the birth day to 1 year. The patients were divided into two groups. In the main group, The EOT was performed using a dental obturator for orthodontic treatment of children with CBCULP before surgery $(n=43)$. In the comparison group, the treatment relied on the non-conventional method $(n=41)$. Prior to the surgery, all the children were examined using clinical, anthropometric and photometric methods. All the newborns in the main group, while remaining in a horizontal position only, had their upper jaw impression taken using an alginate mass, whereas the impression covered the intermaxillary bone. At the time the cast was made, the baby had to be hungry and crying, the cry testifying to its safety. Further, an analysis of the upper jaw cast model was performed followed with production of the obturator for dental orthodontic treatment of CBCULP in children, which can be fixed securely to the upper jaw due to the nasal part with no extra fixing elements involved (Fig. 4).
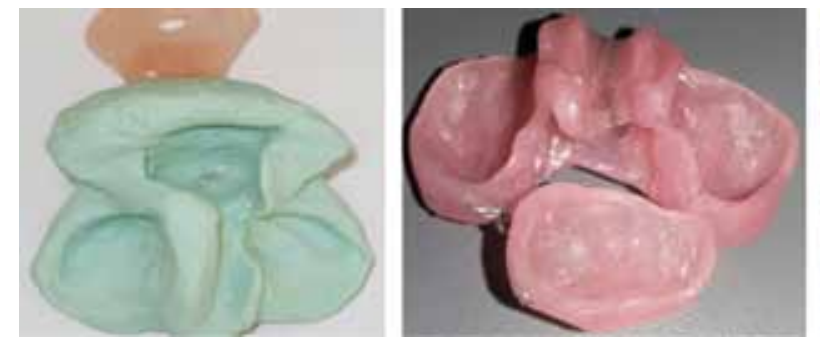

$a$

$b$

The designed obturator helps improve feeding as well as the maxillary alveolar arch shape. There was no protrusion of the jawbone observed, whereas the vomer was located on the symmetry axis.

The statistical processing of the obtained data revealed that before the treatment was started, the groups were comparable in terms of their major indicators, with no statistically significant differences to be observed. Following the treatment, the babies' age, weight, and height changed naturally in both groups $(\mathrm{p}<0.001)$. The jaw cast model parameters in the main group changed significantly, whereas in the comparison group, the treatment was carried out using a rubber elastic bandage. The treatment duration was 6-8 months and depended on the baby's somatic status; there were certain issues observed during feeding injured skin on the upper lip middle at the nostril area. In view of that, there were some corrective measures taken with a new elastic rubber bandage produced. While the conventional method was employed, there was some convergence identified of the maxillary bone with the upper lip middle at the anterior part of upper jaw the alveolar process, as well as a flattening in the upper lip middle. During that, the vomer retained its position with the deformation getting worse. As for the cast model parameters in cases where the conventional treatment method was employed, the observed changes were slight. The only statistically significant change was an $11.7 \%$ decrease in the B-F1 distance $(\mathrm{p}=0.017)$.

A comparison of jaw cast model parameters through the groups undergoing early orthodontic treatment produced the following significant differences: lower $\mathrm{BC}$ values in the main group ( $10.3 \pm 0.9 \mathrm{~mm}$ vs. $16.0 \pm 2.3 \mathrm{~mm}$ in the comparison group, $\mathrm{p}=0.013)$; $\mathrm{EB}(29.4 \pm 1.5 \mathrm{~mm}$ vs. $34.5 \pm 1.3 \mathrm{~mm}$ in the comparison group, $\mathrm{p}=0.033)$ as well as higher $\mathrm{DE}$ values $(36.6 \pm 0.3 \mathrm{~mm}$ vs. $34.0 \pm 0.7 \mathrm{~mm}$ in the comparison group, $\mathrm{p}=0.001)$.

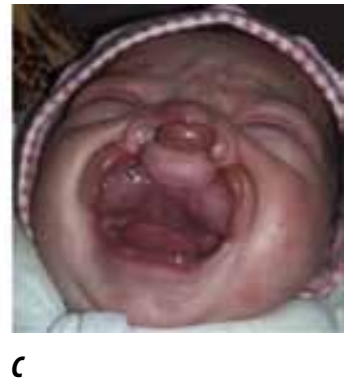

Fig. 4. Impression from the upper jaw produced with a specifically designed spoon (a); inner surface of the dental obturator used to perform orthodontic treatment of CBCUL in children (b); dental obturator in the baby's oral cavity (c)

The study implied effectiveness quantitative assessment of treatment offered to babies with CBCULP based on a specifically developed method, matched against patients treated through a conventional method. Low treatment effectiveness, which manifested itself through insufficient capacity of milksucking and eating independently, was observed in 11 babies from the comparison group (27\%) and only in 2 patients in the main group (5\%). The absolute risk 
reduction (ARR) was $22 \%$ at a CI of $95 \%$ : 6.7-37.7\%. This ARR value corresponds to a NNT of $5(95 \% \mathrm{CI}$ : 3-15). This means that it would take offering the newly developed EOT to 5 children, in order to guarantee respective improvement in one extra child. The relative risk reduction was $82.7 \%$ (95\% CI: 26.4-95.9\%); the odds ratio was 0.13 (95\% CI: $0.03-0.63$ ). The results were considered statistically significant at $\mathrm{p}=0.012$.

\section{CONCLUSION}

The study described above was the first focusing on the frequency and prevalence of CBCULP in babies, embracing the period of 2009-2019 in the municipal areas of Tajikistan. The questionnaire survey carried out among the babies' parents revealed the effect that related marriages have on an increase in the CBCULP occurrence and prevalence rate. The study offered the first ever explanation to the method of employing early orthodontic treatment for babies with CBCULP (RF patent \# 2735063) performed with the dental obturator for orthodontic treatment of children with CBCULP (Republic of Tajikistan patent for invention \# TJ 941) and the obturator for early orthodontic treatment of children with CBCULP (RF patent \# 199314), all this aimed at improving the spatial ratio of the maxillary bone and upper jaw fragments, taken as a preparatory stage for comprehensive treatment. If matched against the conventional treatment, early orthodontic treatment relying on a modified dental obturator used to treat babies with CBCULP, yielded significantly better outcomes.

\section{REFERENCES}

1. Avanisyan V., Al-Harazi G., Kondratyeva T., Harutyunyan Yu. Morphology of facial skeleton in children with undifferentiated connective tissue dysplasia. Archiv EuroMedica. 2020. Vol. 10; 3: 130-141. https://dx.doi.org/10.35630/2199$885 \mathrm{X} / 2020 / 10 / 3.32$

2. Davydov B.N. Anthropometric peculiarities of the maxillofacial region in children with congenital pathology in the period of the brew of the dairy teeth. Pediatric dentistry and prophylaxis. 2018; Vol. 17; 2 (65): 5-12. (In Russ.) DOI: 10.25636/PMP.3.2018.2.1.

3. DAVYdov B.N. Kondratyeva T.A., HaRUTYUNYAN YU.S. Cephalometric features of connective tissue dysplasia manifestation in children and adolescents. Pediatric dentistry and dental profilaxis. 2020;20(3):174-183. (In Russ.) https://doi. org/10.33925/1683-3031-2020-20-3-174-183

4. Davydov, B.N., Kondratyeva, T.A., HarutyUNYAN, YU.S. Improving diagnostics of periodontal diseases in children with connective tissue dysplasia based on X-ray morphometric and densitometric data. Parodontologiya.2020;25(4):266-275. (in Russ.) https://doi.org/10.33925/1683-3759-2020-25-4-266275 .
5. DAVYDOV B.N. Morphological peculiarities of facial skelet structure and clinical and diagnostic approaches to the treatment of dental anomalies in children in the period of early change. Pediatric dentistry and prophylaxis. 2019; Vol. 19; 1 (69): 26-38. (In Russ.) DOI: 10.33925/1683-3031-2019-19-69-26-38

6. DAVYDov B.N. Biometric study of jaw models in evaluation of individual sizes of the dental arches in children with anomalies of occlusion. Pediatric dentistry and prophylaxis. 2016; Vol. 15; 4 (59): 47-52. (In Russ.)

7. DAvydov, B.N. Treatment of congenital bilateral clefts of the upper lip / B.N. Davydov, S.N. Bessonov // Dentistry. - 2013. - No. 2. - P. 60-64.

8. Gubina, L.K. Analysis of the influence of exogenous and endogenous factors on the frequency of congenital clefts of the lip and palate according to the archival data of the city of Voronezh / L.K. Gubina, O. P. Krasnikova // Act. probl., med .: Jubilee Sat. scientific. tr., Voronezh, 1998 . - P. 193-195.

9. HarutyunYan Yu. Undifferentiated connective tissue dysplasia as a key factor in pathogenesis of maxillofacial disorders in children and adolescents. Archiv EuroMedica. 2020. Vol. 10; 2: 83-94. https://dx.doi. org/10.35630/2199-885X/2020/10/2.24

10. Ivanyuta O.P., Al-Harasi G., Kuleshov D.A. Modification of the dental arch shape using graphic reproduction method and its clinical effectiveness in patients with occlusion anomalies // Archiv EuroMedica. 2020. Vol. 10; 4: 181-190. https://dx.doi. org/10.35630/2199-885X/2020/10/4.42

11. Persin, L.S. Orthodontics. National leadership. In 2 volumes. T1. Diagnosis of dentoalveolar anomalies / ed. L.S. Persina. - Moscow: GEOTAR-Media, 2020 . - 304p.

12. Shkarin V.V., Ivanov S.Yu. Morphological specifics of craniofacial complex in people with varioustypes of facial skeleton growth in case of transversal occlusion anomalie. Archiv EuroMedica. 2019. Vol. 9; 2: 5-16. https://doi.org/10.35630/2199-885X/2019/9/2/5

13. Shkarin V.V., Davydov B.N. Non-removable arch orthodontic appliances for treating children with congenital maxillofacial pathologies - efficiency evolution. Archiv EuroMedica, 2018. Vol. 8. № 1. P. 97-98. https://doi.org/10.35630/2199-885X/2018/8/1/97

14. Suetenkov D.Ye., Kharitonova T.L., Danilov A.N., Popkova O.V., Kobets A.V. Dental morbidity in the school-age child population in the Saratov region. - Clinical dentistry. - 2019. - N. 1. - P. 96-99.

15. Malimon, T.V. Complex treatment and rehabilitation of children with congenital cleft lip and palate at the Department of Pediatric Dentistry named after T.V. Ball. / Malimon T.V. [and others] // Congenital and hereditary pathology of the head, face and neck in children: topical issues of complex treatment $-\mathrm{M}$ : MGMSU, 2016. - 346 p.

16. Postnikov, M.A. Problems of rehabilitation of patients with congenital cleft of the upper lip and palate in the Samara region / M.A. Postnikov, N.A. 
Vorozheikina, A.N. Karpov, A.S. Seregin // Pediatric dentistry and prevention. - 2019. - Vol. 19. - No. 1 (69). - P. 15-20. https://doi.org/10.33925/16833031-2019-19-69-15-20.

17. Firsova I.V., Suetenkov D.E., Davydova N.V., OLEINIKOVA N.M. Interrelation and interdependence of the level of dental health and environmental factors // Saratov Journal of Medical Scientific Research. 2011. - Vol. 7. No. 1. - P. 239-245.

18. Seregin, A.S. Congenital cleft of the upper lip and palate: a tutorial / A.S. Seregin, G.N. Belanov, N.V. Nogina, M.A. Postnikov, M.G. Samutkina, D.A. Trunin - Samara: OOO Slovo, 2020. - 152 p.

19. Dolgopolova, G.V. Early orthopedic treatment in the complex rehabilitation of children with congenital cleft of the upper lip, alveolar ridge and palate: author. dis. ... Cand. honey. Sciences: 14.00.21 / Dolgopolova Galina Vladimirovna. - M., 2005 - 25 p.

20. Ishmuratova, A.F. Modern methods of orthodontic treatment / A.F. Ishmuratova, M.A. Postnikov // Dental journal. - 2017. - No. 3. - P. 213 - 219.

21. Mamedov, A.A. An interdisciplinary approach to the treatment of children with cleft lip and palate complicated by palatopharyngeal insufficiency / A.A. Mamedov, O. V. Dudnik, E.A. Zavgorodnaya // Knowledge. - 2019. - No. 4-1 (68). - P. 50-59.

22. Mamedov, A.A. An interdisciplinary approach to the treatment of children with cleft lip and palate during the neonatal period. Mamedov, A.B. McLennan, M.G. Ryabkova, I.M. Donin, Yu.O. Volkov, D.S. Parfenov, D.S. Poluektov, P.V. Novikov, Zh.A. Blinder, L.A. Mazurin, A.I. Kalinina, O. T Zangieva // System integration in health care. - 2017. - No. 2 (31). - P. 52-59.

23. Nikolaeva, E.V. Optimization of dental care for young children with cleft lip and / or palate at the stages of complex treatment: author. dis. ... Cand. honey. Sciences: 14.00.14 / Nikolaeva Elena Vladimirovna. - Kazan, 2014 . - 24p.

24. Stepanov, G.V. Dental clinical examination: a tutorial / G.V. Stepanov, S.E. Chigarina, O.A. Bagdasarova, M.A. Postnikov, S.A. Popov, N.V. Popov, L.G. Ulyanova - Samara: LLC "Publishing and Printing Complex" Pravo", 2019. - 200 p.

25. Abualfaraj R. Cleft lip and palate in context: Learning from, and adding to, the sociological literature on long-term conditions / R. Abualfaraj, B. Daly, F. McDonald, S. Scambler // Health (London). 2017. doi: 10.1177/1363459317693409

26. Almoammar K.A. Cephalometric Soft Tissue Characteristics of Unilateral Cleft Lip and Palate Patients in Relation to Missing Teeth. / K.A. Almoammar, H.A. Almarhoon, W. Batwa, N. Alqahtani, T. AlJewair, S. Albarakati / Biomed Res Int. - 2017. doi: $10.1155 / 2017 / 2392808$.

27. ESENLIK E. Preoperative alveolar segment position as a predictor of successful gingivoperiosteoplasty in patients with unilateral cleft lip and palate // E. Esenlik, J.M. Bekisz, T. Gibson, C.B. Cutting, B.H.
Grayson, R.L. Flores // PlastReconstr Surg. - 2017. doi: 10.1097/PRS.0000000000004231.

28. Felton M. Early placement of ventilation tubes in infants with cleft lip and palate: A systematic review / M. Felton, J.W. Lee, D.D. Balumuka, J.S. Arneja, N.K. Chadha // Otolaryngol Head Neck Surg. - 2017. doi:10.1177/0194599817742840.

29. Grayson B.H., Maull D. Nasoalveolar molding for infants born with clefts of the lip, alveolus, and palate / B.H. Grayson, D. Maull / / Clin Plast Surg. - 2004. - № 31(2). - P. 149. doi:10.1016/S0094$1298(03) 00140-8$

30. Meazzini M.C. Photometric Evaluation in Adolescence of Patients With Bilateral Cleft Lip and Palate Treated With Nasoalveolar Molding and Primary Columella Lengthening / M.C. Meazzini, C. Chiavenna, L. Autelitano, G. Garattini, R. Brusati // Cleft Palate Craniofac J. - 2018. - № 55(4). - P.568-573. doi: $10.1177 / 1055665617732785$

31. Pisek, P. Orthodontic treatment of unilateral cleft lip and alveolus patient with maxillary lateral incisor missing: case report / P. Pisek, M. Manosudprasit, T. Wangsrimongkol, A. Pasasuk, T. Somsuk // J Med Assoc Thai. - 2013. - P.157-163. 